\title{
Densification Behavior of Ti-Doped Polycrystalline Alumina in a Nitrogen-Hydrogen Atmosphere
}

\author{
Hidehiro Yoshida ${ }^{1}$, Keijiro Hiraga ${ }^{1}$ and Takahisa Yamamoto ${ }^{2}$ \\ ${ }^{1}$ Nano Ceramics Center, National Institute for Materials Science, Tsukuba 305-0047, Japan \\ ${ }^{2}$ Department of Advanced Materials Science, Graduate School of Frontier Sciences, The University of Tokyo, \\ Kashiwa 277-8561, Japan
}

The densification behavior during sintering of $0.1 \mathrm{~mol} \% \mathrm{TiO}_{2}$-doped $\mathrm{Al}_{2} \mathrm{O}_{3}$ was measured in either an air or $\mathrm{N}_{2}+5 \% \mathrm{H}_{2}$ gas atmosphere at the sintering temperature of $1573-1673 \mathrm{~K}$. The grain boundary diffusivity was evaluated from the densification rate. High-resolution transmission electron microscopy (HRTEM) and nano-probe energy-dispersive X-ray spectroscopy (EDS) analyses revealed that the doped Ti cations segregate in the vicinity of the grain boundaries in the $\mathrm{Al}_{2} \mathrm{O}_{3}$. An electron energy loss spectroscopy (EELS) investigation indicated that the valence state of $\mathrm{Ti}$ in the $\mathrm{Al}_{2} \mathrm{O}_{3}$ sintered in the reducing atmosphere was close to +3 . The grain boundary diffusivity in undoped $\mathrm{Al}_{2} \mathrm{O}_{3}$ was insensitive to the atmosphere, but was enhanced by the grain boundary segregation of $\mathrm{Ti}^{4+}$. The grain boundary diffusivity of alumina in the reducing atmosphere was, however, retarded by the $\mathrm{Ti}^{3+}$-doping. The retarded diffusivity by $\mathrm{Ti}^{3+}$-doping must be related to the lack of aluminum vacancies and the large ionicity of Ti-O compared to Al-O. [doi:10.2320/matertrans.MC200829]

(Received November 5, 2008; Accepted January 19, 2009; Published April 25, 2009)

Keywords: alumina, titanium-doped alumina, sintering, grain boundary, diffusivity

\section{Introduction}

High-temperature matter transport phenomena, such as densification during sintering in fine-grained, polycrystalline $\mathrm{Al}_{2} \mathrm{O}_{3}$, is often rate-controlled by grain boundary diffusion. $^{1-4)}$ For example, in the hot-isostatic pressing diagram of $\mathrm{Al}_{2} \mathrm{O}_{3}$ constructed by Ashby's group, ${ }^{1)}$ the grain boundary diffusion is the predominant process over a wide range of temperatures and pressures. In addition, it is wellknown that the sintering behavior in alumina is sensitive to small levels of doping of various cations and the atmosphere during sintering, ${ }^{2-7)}$ for instance, the translucent alumina polycrystal is generally fabricated by sintering in a $\mathrm{H}_{2}$ atmosphere. ${ }^{7)}$ The dependence of the grain boundary diffusivity on the dopant cations and the sintering atmosphere is therefore important information for fabricating high-performance $\mathrm{Al}_{2} \mathrm{O}_{3}$ ceramics. In fact, many studies have been conducted on the effect of sintering aids on the sintering of alumina. In contrast, only a few studies have been conducted on the effect of the sintering atmosphere on the sintering behavior.

The grain boundary diffusivity in $\mathrm{Al}_{2} \mathrm{O}_{3}$ has been previously estimated from neck growth during the initial stage of sintering, ${ }^{8)}$ creep deformation ${ }^{9,10)}$ and densification rate during the final stage of sintering ${ }^{2,11)}$ owing to the difficulties in the direct measurement of the grain boundary diffusivity by the tracer method. ${ }^{12)}$ Our group has recently measured the grain boundary diffusivity of various kinds of cation-doped alumina from the densification rate during the sintering experiment by using a scanning-laser micrometer system. ${ }^{6)}$ This study aims to measure the densification behavior of $0.1 \mathrm{~mol} \% \mathrm{TiO}_{2}$ doped $\mathrm{Al}_{2} \mathrm{O}_{3}$ during sintering in either an air or $\mathrm{N}_{2}+\mathrm{H}_{2}$ atmosphere as the first step of elucidating the effect of atmosphere on the sintering of alumina. The microstructure and valence state of $\mathrm{Ti}$ in the present materials were also investigated.

\section{Experimental Procedure}

The materials used in this study were undoped, high-purity $\mathrm{Al}_{2} \mathrm{O}_{3}$ and $0.1 \mathrm{~mol} \% \quad \mathrm{TiO}_{2}$-doped $\mathrm{Al}_{2} \mathrm{O}_{3}$. Commercially available $\alpha-\mathrm{Al}_{2} \mathrm{O}_{3}$ powder with a purity of $99.99 \%$ and average particle size of $130 \mathrm{~nm}$ (TM-DAR; Taimei Chemistry) was used as the base material. The dopant was titanium oxide (nano-powder; Aldrich) with a particle size of 25$70 \mathrm{~nm}$ and purity of $3 \mathrm{~N}$. The $\mathrm{Al}_{2} \mathrm{O}_{3}$ powders and the dopant oxide were ball-milled using alumina balls in ethanol for $24 \mathrm{~h}$, dried and sifted through a 60 mesh sieve for granulation. The green compacts were prepared by pressing the mixed powders into a cylindrical shape at a pressure of $30 \mathrm{MPa}$, and then isostatically pressed at a pressure of $400 \mathrm{MPa}$. The dimensions of the samples were about $15 \mathrm{~mm}$ in diameter and about $18 \mathrm{~mm}$ in length.

The sintering experiment was carried out in an alumina tube furnace that was externally heated by a molybdenum disilicide heater in either air or flowing $\mathrm{N}_{2}+5 \% \mathrm{H}_{2}$ gas (1atm) atmosphere; it has been reported that sintering in a $\mathrm{N}_{2}+\mathrm{H}_{2}$ atmosphere with a $\mathrm{H}_{2}$ content of $2-8 \%$ is feasible for the fabrication of translucent alumina polycrystals. ${ }^{7}$ ) Specimen shrinkage was measured using a laser-scanning micrometer with a resolution of $\pm 3 \mu \mathrm{m}$ (LS-7070; Keyence, Japan) from room temperature to the sintering temperature of 1573-1673 K. Figure 1 shows a schematic illustration of the furnace and attached laser-scanning system. The semiconductor laser generator projects a strip-shaped beam through the alumina tube to the detector at a wavelength of $520 \mathrm{~nm}$ with laser scans of $2400 \mathrm{scans} / \mathrm{s}$. The specimen shrinkage was calculated from the time-dependent diameter of the cylindrical specimen $L$. The temperature of the specimen was measured by a Pt-PtRh thermocouple placed close to the specimen in the alumina tube. The specimen was heated to its sintering temperature at $10^{\circ} \mathrm{C} / \mathrm{min}$ then held for $2 \mathrm{~h}$.

The microstructures of the present materials were observed by scanning electron microscopy (SEM) and high-resolution 


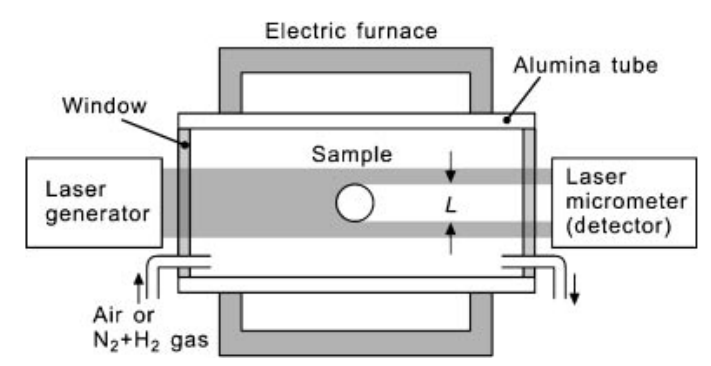

Fig. 1 A schematic illustration of the furnace and scanning-laser micrometer used for the measurement of the densification behavior.
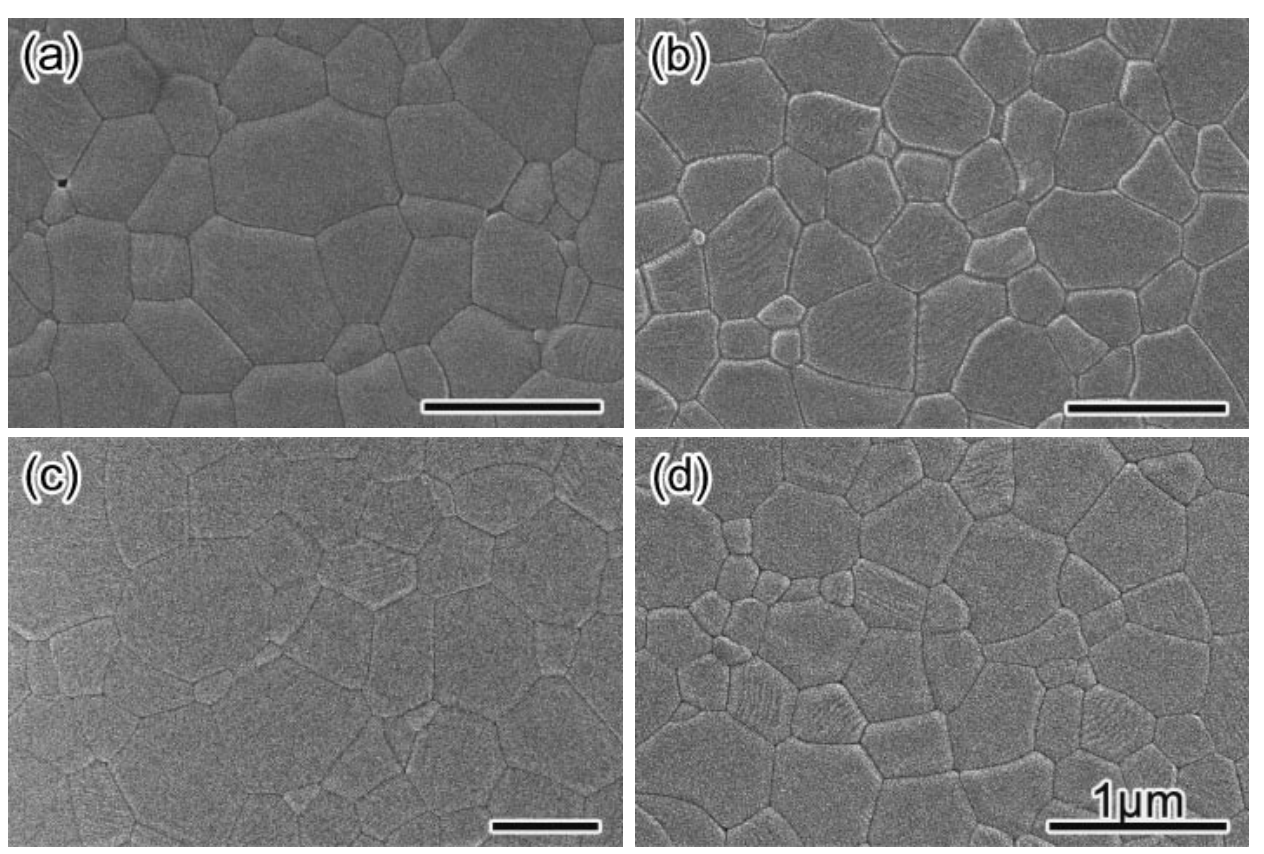

Fig. 2 SEM micrographs of undoped $\mathrm{Al}_{2} \mathrm{O}_{3}$ s sintered in the (a) air and (b) $\mathrm{N}_{2}+5 \% \mathrm{H}_{2}$ atmosphere and $0.1 \mathrm{~mol} \% \mathrm{TiO}_{2}$-doped $\mathrm{Al}_{2} \mathrm{O}_{3}$ sintered in the (c) air and (d) $\mathrm{N}_{2}+5 \% \mathrm{H}_{2}$ atmosphere. The sintering temperature was $1573 \mathrm{~K}$.

transmission electron microscopy (HRTEM). The average grain sizes of the present materials were measured by the linear intercept method based on more than 300 grains in the SEM photographs. The TEM specimens were prepared using standard techniques involving mechanical grinding to a thickness of less than $0.1 \mathrm{~mm}$, and ion beam milling to an electron transparency at about $4 \mathrm{kV}$. For analysis of the $\mathrm{Ti}$ distributions in the $\mathrm{Al}_{2} \mathrm{O}_{3}$, an energy-dispersive X-ray spectroscopy (EDS) analysis was also performed using the Noran Voyager system attached to a Topcon EM-002BF field emission microscope with a focused beam size of about $1 \mathrm{~nm}$. The electron energy loss spectrometry (EELS; Enfina spectrometer, Gatan Co., Ltd.) measurements were carried out in the HRTEM at twelve different grain boundaries in each sample with the probe size of about $1 \mathrm{~nm}$. The full width at half maximum of the zero-loss peak was $1.4 \mathrm{eV}$ under the present condition, and the energy resolution of the EELS was $0.2 \mathrm{eV}$.

\section{Results and Discussion}

Figure 2 shows SEM images of the undoped $\mathrm{Al}_{2} \mathrm{O}_{3} \mathrm{~s}$ sintered in (a) air and (b) $\mathrm{N}_{2}+\mathrm{H}_{2}$ atmosphere and of the $0.1 \mathrm{~mol} \% \mathrm{TiO}_{2}$-doped $\mathrm{Al}_{2} \mathrm{O}_{3} \mathrm{~s}$ sintered in (c) air and (d) $\mathrm{N}_{2}+\mathrm{H}_{2}$. The sintering temperature was $1573 \mathrm{~K}$ for the
Table 1 Average grain size of undoped and $0.1 \mathrm{~mol} \% \mathrm{TiO}_{2}$-doped $\mathrm{Al}_{2} \mathrm{O}_{3} \mathrm{~S}$ sintered in either the air or $\mathrm{N}_{2}+\mathrm{H}_{2}$ gas atmosphere.

\begin{tabular}{|c|c|c|c|c|c|}
\hline & \multirow{3}{*}{$\begin{array}{c}\text { Material } \\
\text { Atmosphere }\end{array}$} & \multicolumn{4}{|c|}{ Average grain size $/(\mu \mathrm{m})$} \\
\hline & & \multicolumn{2}{|c|}{ undoped- $\mathrm{Al}_{2} \mathrm{O}_{3}$} & \multicolumn{2}{|c|}{$\mathrm{Al}_{2} \mathrm{O}_{3}+\mathrm{TiO}_{2}$} \\
\hline & & Air & $\mathrm{N}_{2}+5 \% \mathrm{H}_{2}$ & Air & $\mathrm{N}_{2}+5 \% \mathrm{H}_{2}$ \\
\hline \multirow{3}{*}{ 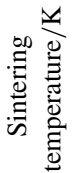 } & 1573 & 0.83 & 0.73 & 1.20 & 0.61 \\
\hline & 1623 & 1.70 & 1.96 & 1.97 & 1.45 \\
\hline & 1673 & 3.17 & 2.26 & 4.67 & 2.08 \\
\hline
\end{tabular}
consist of equiaxed alumina grains without any abnormal grain growth. In addition, the relative density of the sintered samples reached more than $99 \%$ for the examined sintering conditions. Table 1 shows the average grain size of the present materials sintered at $1573-1673 \mathrm{~K}$. The grain sizes were in the range of $1-5 \mu \mathrm{m}$. In the $\mathrm{Al}_{2} \mathrm{O}_{3}$ s sintered in air, the grain size is increased by the Ti-doping at the examined sintering temperatures. In contrast, the grain sizes in the undoped and $\mathrm{TiO}_{2}$-doped $\mathrm{Al}_{2} \mathrm{O}_{3}$ s sintered in the $\mathrm{N}_{2}+\mathrm{H}_{2}$ atmosphere are smaller than those in the materials sintered in air. The sintering in the reducing atmosphere can effectively suppress the grain size of the alumina.

The HRTEM observations indicated that no second phase particle or amorphous layer exists at the grain boundary of the $\mathrm{TiO}_{2}$-doped $\mathrm{Al}_{2} \mathrm{O}_{3}$ s sintered in the air and $\mathrm{N}_{2}+\mathrm{H}_{2}$ gas atmospheres. Figure 3 shows the EDS spectra obtained at a grain boundary, at $5 \mathrm{~nm}$ and $10 \mathrm{~nm}$ from the grain boundary, and at the grain interior in the $\mathrm{TiO}_{2}$-doped $\mathrm{Al}_{2} \mathrm{O}_{3}$ sintered in $\mathrm{N}_{2}+\mathrm{H}_{2}$ at $1573 \mathrm{~K}$. The size of the electron beam was about $1 \mathrm{~nm}$. Ti cations can be detected at the grain boundary and slightly detected $5 \mathrm{~nm}$ from the grain boundary, but cannot be observed at $10 \mathrm{~nm}$ from the grain boundary and the grain interior. These results indicate that the doped $\mathrm{Ti}$ cations 


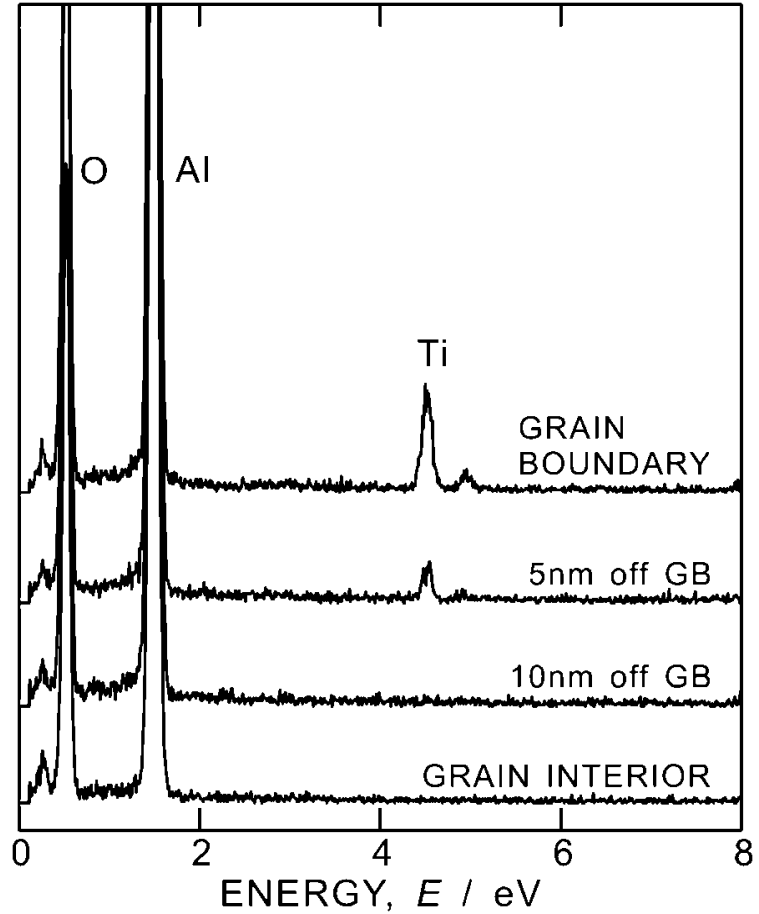

Fig. 3 EDS spectra obtained at the grain boundary, at $5 \mathrm{~nm}$ and $10 \mathrm{~nm}$ from the grain boundary, and the grain interior in the Ti-doped $\mathrm{Al}_{2} \mathrm{O}_{3}$ sintered in the $\mathrm{N}_{2}+\mathrm{H}_{2}$ atmosphere at $1573 \mathrm{~K}$.

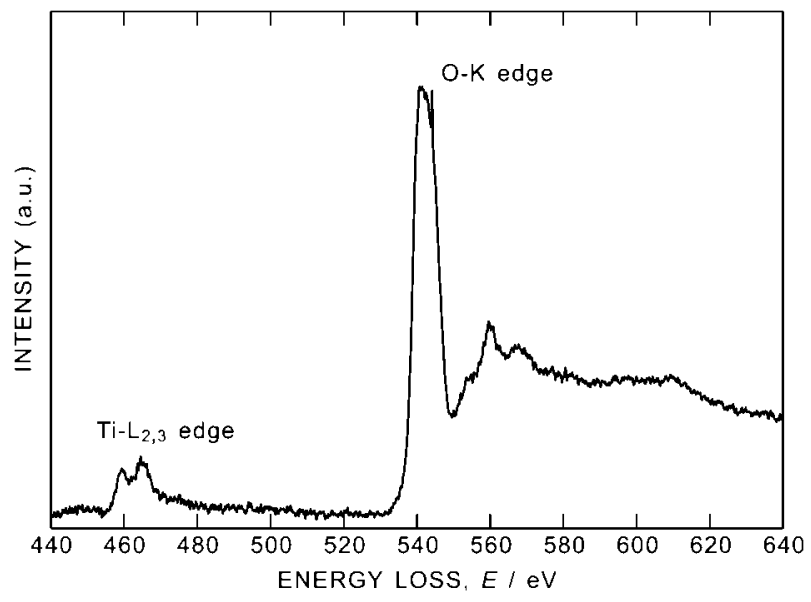

Fig. 4 An EELS spectrum acquired at the grain boundary in the Ti-doped $\mathrm{Al}_{2} \mathrm{O}_{3}$ sintered in the $\mathrm{N}_{2}+\mathrm{H}_{2}$ atmosphere at $1573 \mathrm{~K}$.

segregate in the vicinity of the grain boundaries in $\mathrm{Al}_{2} \mathrm{O}_{3}$. Our previous studies revealed that a small amount of doped cations tends to segregate in the vicinity of the grain boundaries in polycrystalline $\mathrm{Al}_{2} \mathrm{O}_{3}$ sintered in air. ${ }^{13-17)}$ The present result of the $\mathrm{TiO}_{2}$-doped $\mathrm{Al}_{2} \mathrm{O}_{3}$ sintered in the reducing atmosphere is consistent with the previous reports for that sintered in air.

Figure 4 shows an EELS spectrum for the $\mathrm{TiO}_{2}$-doped $\mathrm{Al}_{2} \mathrm{O}_{3}$ s sintered in the $\mathrm{N}_{2}+\mathrm{H}_{2}$ atmosphere at $1573 \mathrm{~K}$. The Ti- $L_{2,3}$ and $\mathrm{O}-K$ edges can be seen in the spectrum, though the intensity of the Ti- $L_{2,3}$ edge is fairly weak compared to the $\mathrm{O}-K$ edge. Figure 5(a) shows the typical electron energyloss near-edge fine structure (ELNES) of the Ti- $L_{2,3}$ edges obtained from the $\mathrm{TiO}_{2}$-doped $\mathrm{Al}_{2} \mathrm{O}_{3} \mathrm{~s}$ sintered in the air and $\mathrm{N}_{2}+\mathrm{H}_{2}$ atmospheres at $1573 \mathrm{~K}$. For comparison, the
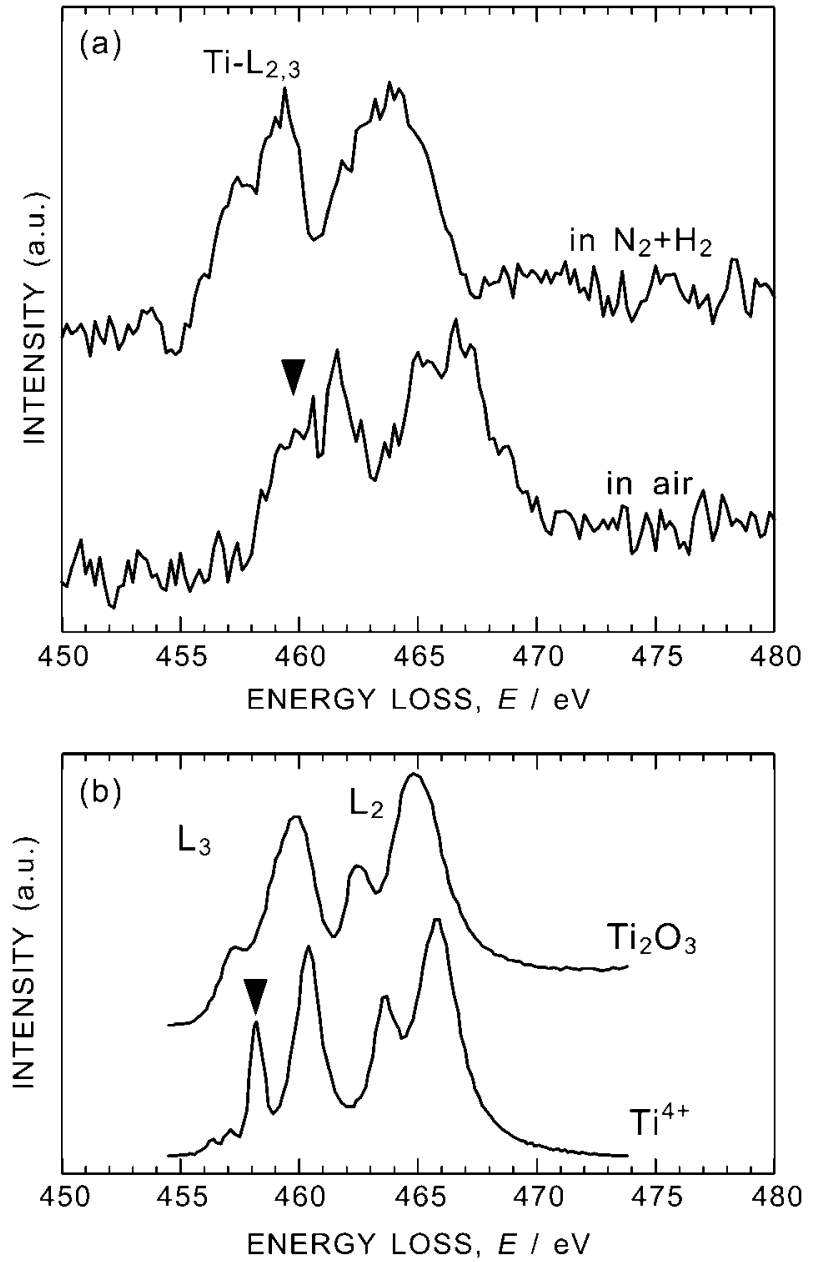

Fig. 5 (a) Ti- $L_{2,3}$ ELNESs acquired at the grain boundaries in the Ti-doped $\mathrm{Al}_{2} \mathrm{O}_{3}$ s sintered in the air and $\mathrm{N}_{2}+\mathrm{H}_{2}$ atmospheres at $1573 \mathrm{~K}$. (b) The reference data of $\mathrm{Ti}-L_{2,3}$ ELNESs of $\mathrm{Ti}_{2} \mathrm{O}_{3}$ and $\mathrm{Ti}^{4+}$ in the octahedral crystal field. ${ }^{17)}$

reference data of Ti- $L_{2,3}$ edge ELNESs for $\mathrm{Ti}_{2} \mathrm{O}_{3}\left(\mathrm{Ti}^{3+}\right)$ and $\mathrm{Ti}^{4+}$ in octahedral crystal field are shown in Fig. 5(b). ${ }^{18)}$ A previous study of the $\mathrm{TiO}_{2}$-doped $\mathrm{Al}_{2} \mathrm{O}_{3}$ single crystal indicates that annealing in air converts the titanium to a valence state of $\left.\mathrm{Ti}^{4+} .{ }^{19}\right)$ Therefore, the $\mathrm{Ti}$ in the present $\mathrm{Al}_{2} \mathrm{O}_{3}$ sintered in air must be in the quadrivalent state. The Ti- $L_{2,3}$ edge of the $\mathrm{Al}_{2} \mathrm{O}_{3}$ sintered in air in Fig. 5(a) probably reflects the $\mathrm{Ti}^{4+}$ state, though the present $\mathrm{Ti}-L_{2,3}$ edge ELNES for the $\mathrm{Al}_{2} \mathrm{O}_{3}$ sintered in air is observed at about $1 \mathrm{eV}$ higher energy than the reference data of $\mathrm{Ti}^{4+}$. On the other hand, the $\mathrm{Ti}-L_{2,3}$ edge in the $\mathrm{TiO}_{2}$-doped $\mathrm{Al}_{2} \mathrm{O}_{3}$ sintered in $\mathrm{N}_{2}+\mathrm{H}_{2}$ is observed at 2-3eV lower energy in comparison to the $\mathrm{TiO}_{2}$-doped $\mathrm{Al}_{2} \mathrm{O}_{3}$ sintered in air. The Ti- $L_{2,3}$ edge in the $\mathrm{Al}_{2} \mathrm{O}_{3}$ sintered in $\mathrm{N}_{2}+\mathrm{H}_{2}$ has a tendency to be observed at $1-3 \mathrm{eV}$ lower energy for all the examined grain boundaries. In addition, a small additional peak at $459-461 \mathrm{eV}$ (indicated by the black inverted triangle in Fig. 5(a)) is more apparent in the Ti- $L_{2,3}$ edge of the $\mathrm{Al}_{2} \mathrm{O}_{3}$ sintered in air. The differences in the ELNESs are perhaps attributed to the valence state of Ti. It has been pointed out that the Ti- $L_{2,3}$ edge in $\mathrm{Ti}_{2} \mathrm{O}_{3}$ shifts to the low energy side compared to the Ti- $L_{2,3}$ ELNES of $\mathrm{Ti}^{4+}{ }^{18)}$ In addition, the first peak at $458 \mathrm{eV}$ (indicated by the black inverted triangle in Fig. 5(b)) is prominent in $\mathrm{Ti}^{4+}$ in comparison with $\mathrm{Ti}_{2} \mathrm{O}_{3} .{ }^{18)}$ From the differences in the 


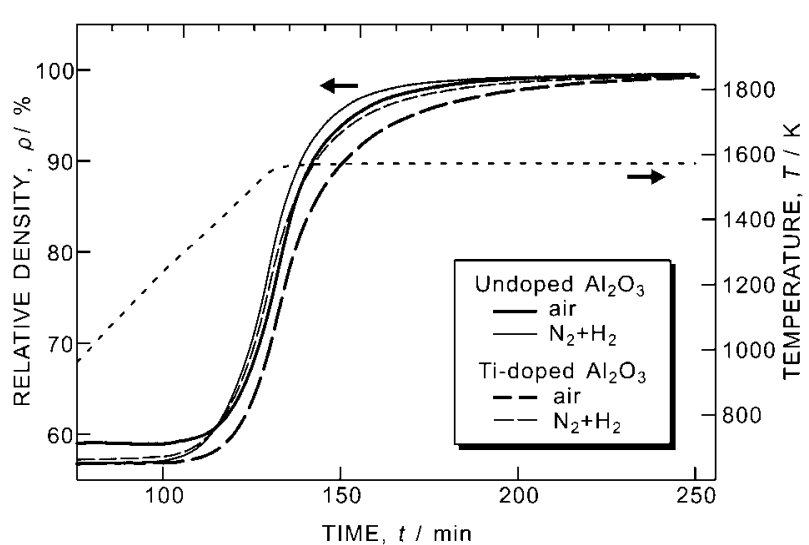

Fig. 6 The change in the relative density during sintering in the undoped, high-purity $\mathrm{Al}_{2} \mathrm{O}_{3}$ and Ti-doped $\mathrm{Al}_{2} \mathrm{O}_{3}$ sintered in either the air or $\mathrm{N}_{2}+\mathrm{H}_{2}$ atmosphere at $1573 \mathrm{~K}$. The temperature of the specimen is also depicted.

reference $\mathrm{Ti}-L_{2,3}$ ELNESs, the valence state of $\mathrm{Ti}$ in the $\mathrm{TiO}_{2}$-doped $\mathrm{Al}_{2} \mathrm{O}_{3}$ sintered in $\mathrm{N}_{2}+\mathrm{H}_{2}$ is probably closer to +3 , rather than +4 .

Figure 6 shows the change in the relative density during sintering of the undoped and $0.1 \mathrm{~mol} \% \mathrm{TiO}_{2}$-doped $\mathrm{Al}_{2} \mathrm{O}_{3} \mathrm{~s}$ in either the air or $\mathrm{N}_{2}+\mathrm{H}_{2}$ at the sintering temperature of $1573 \mathrm{~K}$. The temperature of the specimens is also depicted by the dotted line in Fig. 6. Rapid densification begins at the temperature of around $1273-1373 \mathrm{~K}$ in all of the materials, and the relative density becomes greater than $99 \%$ after the sintering. The densification of the undoped and $\mathrm{TiO}_{2}$-doped $\mathrm{Al}_{2} \mathrm{O}_{3} \mathrm{~S}$ is enhanced by the sintering in the reducing atmosphere. The densification rate of $\mathrm{Al}_{2} \mathrm{O}_{3}$ seems to be retarded by the doping of $\mathrm{TiO}_{2}$ in both the air and $\mathrm{N}_{2}+\mathrm{H}_{2}$ atmospheres. It has been reported that the grain boundary diffusion dominates the densification rate in $\mathrm{Al}_{2} \mathrm{O}_{3}$ for a grain size of less than $10 \mu \mathrm{m} .{ }^{20)}$ Since the densification is ratecontrolled by the grain boundary diffusivity, and since the doped $\mathrm{Ti}$ cations tend to segregate at the grain boundaries, the origin of the $\mathrm{TiO}_{2}$-doping effect on the densification behavior must result from a change in the grain boundary diffusivity. However, because the grain size of the present materials depends on the $\mathrm{TiO}_{2}$-doping and other sintering conditions, it is necessary to examine the grain boundary diffusivity from the densification rate.

Final-stage sintering, in which residual pores are at multiple junctions, ${ }^{21)}$ can be theoretically described by the rate equation proposed by Ashby's group; ${ }^{1,22)}$

$$
\dot{\rho}=\frac{54 \Omega\left(\delta D_{\mathrm{gb}}+r D_{1}\right)}{k T d^{3}} 5(1-\rho)^{1 / 2}\left(P_{\mathrm{e}}-P_{\mathrm{i}}+\frac{2 \gamma}{r}\right)
$$

where $\rho$ is the relative density of the specimen, $\Omega$ is the atomic volume, $\delta$ is the boundary thickness, $D_{\mathrm{gb}}$ is the grain boundary diffusion coefficient, $D_{1}$ is the lattice diffusion coefficient, $r$ is the pore radius during the final stage of sintering, $d$ is the grain radius, $\gamma$ is the surface energy, $P_{\mathrm{e}}$ is the atmospheric pressure, $P_{\mathrm{i}}$ is the internal pore pressure, $k$ is the Boltzmann constant and $T$ is the absolute temperature. For pressure-less sintering, however, $P_{\mathrm{e}}-P_{\mathrm{i}}$ in the external pressure term $\left(P_{\mathrm{e}}-P_{\mathrm{i}}+2 \gamma / r\right)$ is negligible, and the densification rate of high-purity $\mathrm{Al}_{2} \mathrm{O}_{3}$ takes place mainly by grain boundary diffusion. ${ }^{11)}$ Taking into account the actual dis-

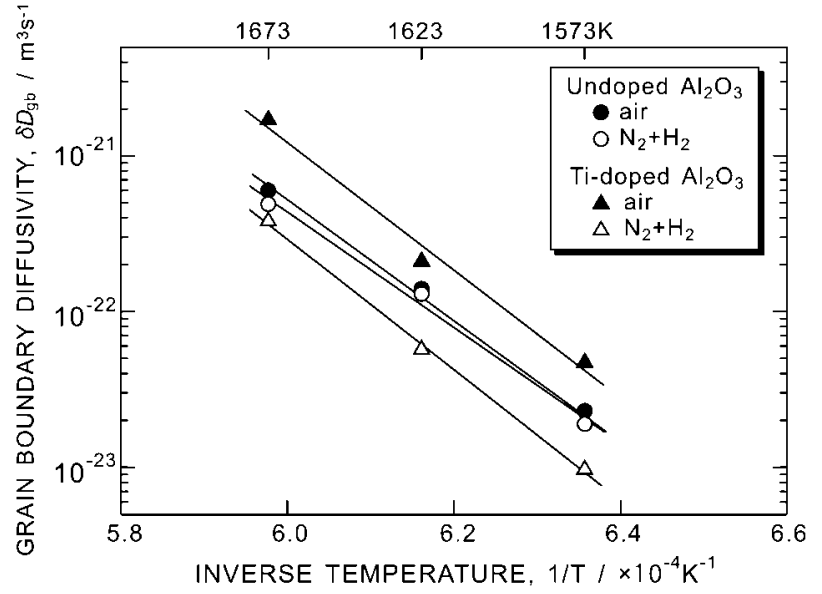

Fig. 7 An Arrhenius plot of the grain boundary diffusivity versus the inverse temperature in the undoped and Ti-doped $\mathrm{Al}_{2} \mathrm{O}_{3} \mathrm{~s}$ sintered in either the air or $\mathrm{N}_{2}+\mathrm{H}_{2}$ atmosphere.

tribution of residual pores and decreasing number of pores during sintering, the densification rate eq. (1) has been modified as follows: ${ }^{11)}$

$$
\dot{\rho}=\left(\frac{0.3}{1-\rho}\right)^{-4 / 3} \frac{54 \Omega \delta D_{\mathrm{gb}}}{k T d^{3}} 5(1-\rho)^{1 / 2} \frac{2 \gamma}{r} .
$$

As such, for the present analysis, the modified densification rate eq. (2) was then used. The value of $\delta D_{\mathrm{gb}}$ can be estimated by minimizing the sum of the residue least squares of the densification curves using eq. (2). For the calculation, $\Omega$ of $4.25 \times 10^{-29} \mathrm{~m}^{3},{ }^{22)}$ and $\gamma$ of $1 \mathrm{Jm}^{-2}$ were used, and the values of $d$ and $r$ were approximated by those measured from the SEM micrographs of the as-sintered materials.

Figure 7 shows an Arrhenius plot of the estimated $\delta D_{\mathrm{gb}}$ versus the inverse temperature for the undoped and $0.1 \mathrm{~mol} \%$ $\mathrm{TiO}_{2}$-doped $\mathrm{Al}_{2} \mathrm{O}_{3}$ s sintered in the air and $\mathrm{N}_{2}+\mathrm{H}_{2}$ atmospheres. The grain boundary diffusivity in the undoped $\mathrm{Al}_{2} \mathrm{O}_{3}$ sintered in $\mathrm{N}_{2}+\mathrm{H}_{2}$ is slightly lower than that in the undoped $\mathrm{Al}_{2} \mathrm{O}_{3}$ sintered in air. It has been pointed out that the hightemperature creep rate in high-purity polycrystalline $\mathrm{Al}_{2} \mathrm{O}_{3}$ is insensitive to the oxygen partial pressure. ${ }^{5)}$ Therefore, it is possible that the grain boundary diffusivity is only slightly changed by the reducing atmosphere. On the other hand, the diffusivity in the $\mathrm{TiO}_{2}$-doped $\mathrm{Al}_{2} \mathrm{O}_{3}$ sintered in air is greater than that in the undoped $\mathrm{Al}_{2} \mathrm{O}_{3} \mathrm{~s}$. The previous studies revealed that the $\mathrm{Ti}^{4+}\left(\mathrm{TiO}_{2}\right)$ addition enhances the grain boundary diffusivity in alumina. ${ }^{6,16,23)}$ In addition, it has been reported that the addition of $\mathrm{Ti}^{4+}$ in $\mathrm{Al}_{2} \mathrm{O}_{3}$ is likely accommodated by the formation of aluminum vacancies. ${ }^{24,25)}$ According to the theoretical study on the energy of the point defects in the $\mathrm{Ti}^{4+}$-doped $\mathrm{Al}_{2} \mathrm{O}_{3},{ }^{24)}$ the following process for dissolution of $\mathrm{Ti}^{4+}$ into $\mathrm{Al}_{2} \mathrm{O}_{3}$ should take place;

$$
\mathrm{TiO}_{2} \rightarrow \mathrm{Ti}_{\mathrm{Al}}^{\bullet}+\frac{1}{3} \mathrm{~V}_{\mathrm{Al}}^{\prime \prime \prime}+2 \mathrm{O}_{\mathrm{O}}
$$

where $\mathrm{Ti}_{\mathrm{Al}}^{\bullet}$ is a titanium cation $\left(\mathrm{Ti}^{4+}\right)$ substituted for an aluminum cation $\left(\mathrm{Al}^{3+}\right)$ with a unit positive charge, $\mathrm{V}_{\mathrm{Al}}^{\prime \prime \prime}$ is a vacant lattice site of $\mathrm{Al}^{3+}$ with three units of negative charge, and $\mathrm{O}_{\mathrm{O}}$ is an oxygen anion $\left(\mathrm{O}^{2-}\right)$ on $\mathrm{O}^{2-}$ site. The formation of $\mathrm{Al}$ vacancies must increase the diffusivity of $\mathrm{Al}_{2} \mathrm{O}_{3}$. The enhanced grain boundary diffusion due to the grain boundary 
segregation of $\mathrm{Ti}^{4+}$ is consistent with the previous results. However, the grain boundary diffusivity in the $\mathrm{TiO}_{2}$-doped $\mathrm{Al}_{2} \mathrm{O}_{3}$ sintered in $\mathrm{N}_{2}+\mathrm{H}_{2}$ is lower than those of the undoped $\mathrm{Al}_{2} \mathrm{O}_{3} \mathrm{~s}$. Assuming that the valence state of $\mathrm{Ti}$ is +3 in the $\mathrm{TiO}_{2}$-doped $\mathrm{Al}_{2} \mathrm{O}_{3}$ sintered in $\mathrm{N}_{2}+\mathrm{H}_{2}, \mathrm{Ti}^{3+}$ can segregate without any aluminum vacancies, and the grain boundary diffusivity should be almost unchanged. Therefore, the result in Fig. 7 indicates that another factor must influence the grain boundary diffusivity in alumina.

Our group has recently found out that the high-temperature creep rate and grain boundary diffusion coefficient in various kinds of cation-doped $\mathrm{Al}_{2} \mathrm{O}_{3}$ s correlate well with the ionicity that can be obtained by molecular orbital calculations. ${ }^{6,15,16)}$ The previous results indicate that the high-temperature matter transport in $\mathrm{Al}_{2} \mathrm{O}_{3}$ increases with the decreasing absolute value of the effective ionic charge. The effective ionic valence in the $\mathrm{Al}$ cation and $\mathrm{O}$ anion must correspond to Coulomb's attractive force between the ions. ${ }^{26)}$ In addition, based on Pauling's electronegativity scale, the ionic bond is a major part of the binding force of $\mathrm{Al}_{2} \mathrm{O}_{3} \cdot{ }^{26)}$ It is therefore reasonable that the atomic diffusion in alumina is influenced by the ionic bonding strength. The Pauling electronegativity values of $\mathrm{Al}$ and $\mathrm{Ti}$ are reported to be 1.61 and 1.54 , respectively. ${ }^{27)}$ The electronegativity is a semi-empirical index of the chemical bonding state, however, the low electronegativity of $\mathrm{Ti}$ suggests that a chemical bond between $\mathrm{Ti}$ and $\mathrm{O}$ gives rise to a large ionicity compared to the Al-O bond. The grain boundary segregation of $\mathrm{Ti}^{3+}$ may increase the ionicity and thereby decrease the grain boundary diffusivity of alumina.

It has recently been reported that the relative surface energy (normalized by surface energy of (0001) plane) in sapphire is increased by Ti-doping. ${ }^{23)}$ Because the surface and grain boundary energies must influence the densification behavior and related microstructural development during the sintering of alumina, the interfacial energies must be investigated in cation-doped polycrystalline alumina as a future study. In addition, further investigation into the chemical bonding state is necessary to provide more atomistic information on the high-temperature grain boundary diffusivity and to elucidate the effect of the atmosphere and cation-doping on the sintering of polycrystalline $\mathrm{Al}_{2} \mathrm{O}_{3}$.

\section{Conclusion}

The densification behavior during sintering in $0.1 \mathrm{~mol} \%$ $\mathrm{TiO}_{2}$-doped $\mathrm{Al}_{2} \mathrm{O}_{3}$ was measured in either an air or $\mathrm{N}_{2}+5 \% \mathrm{H}_{2}$ gas atmosphere at the sintering temperatures of $1573-1673 \mathrm{~K}$. In addition, the HRTEM-EDS analysis and EELS investigation were carried out to examine the distribution and valence state of $\mathrm{Ti}$ in $\mathrm{Al}_{2} \mathrm{O}_{3}$. The results are summarized as follows:

(1) Ti cations tend to segregate in the vicinity of the grain boundary in $\mathrm{Al}_{2} \mathrm{O}_{3}$ s sintered in air and $\mathrm{N}_{2}+\mathrm{H}_{2}$ gas atmospheres.

(2) The Ti- $L_{2,3}$ ELNES investigation suggests that the valence state of $\mathrm{Ti}$ in $\mathrm{TiO}_{2}$-doped $\mathrm{Al}_{2} \mathrm{O}_{3}$ sintered in $\mathrm{N}_{2}+\mathrm{H}_{2}$ is close to +3 , while the valence of $\mathrm{Ti}$ is +4 in $\mathrm{Al}_{2} \mathrm{O}_{3}$ sintered in air.

(3) The grain boundary diffusivity in undoped $\mathrm{Al}_{2} \mathrm{O}_{3}$ was insensitive to the atmosphere, but was enhanced by the grain boundary segregation of $\mathrm{Ti}^{4+}$.

(4) The grain boundary diffusivity of alumina was suppressed by $\mathrm{Ti}^{3+}$-doping. The retarded diffusivity due to the grain boundary segregation of $\mathrm{Ti}^{3+}$ must be related to the lack of aluminum vacancies and the large ionicity of Ti-O compared to Al-O.

\section{Acknowledgments}

The authors wish to express their gratitude to the Ministry of Education, Culture, Sports, Science and Technology and the Japan Society for the Promotion of Science for the financial support by a Grant-in-Aid for Scientific Research on Priority Areas 474-19053008 and for Young Scientists (A)-19686042.

\section{REFERENCES}

1) E. Arzt, M. F. Ashby and K. E. Easterling: Metall. Trans. A 14 (1983) 211-221.

2) J. Wang and R. Raj: J. Am. Ceram. Soc. 73 (1990) 1172-1175

3) R. D. Bagley, I. B. Cutler and D. L. Johnson: J. Am. Ceram. Soc. 53 (1970) 136-141.

4) W. C. Johnson and R. L. Coble: J. Am. Ceram. Soc. 61 (1978) 110-114.

5) R. S. Gordon: Advances in Ceramics, vol. 10, ed. by W. D. Kingery, (Am. Ceram. Soc., Columbus, OH, 1984) pp. 418-437.

6) H. Yoshida, S. Hashimoto and T. Yamamoto: Acta Mater. 53 (2005) 433-440.

7) G. C. Wei and W. H. Rhodes: J. Am. Ceram. Soc. 83 (2000) 16411648 .

8) K. Asaga and K. Hamano: J. Ceram. Soc. Japan 83 (1975) 136-142.

9) A. Mocellin and W. D. Kingery: J. Am. Ceram. Soc. 54 (1971) 339341.

10) R. M. Cannon, W. H. Rhodes and A. H. Heuer: J. Am. Ceram. Soc. 63 (1980) 46-53.

11) H. Harada and T. Sakuma: J. Ceram. Soc. Japan 99 (1991) 136-140.

12) J. H. Harding, K. J. W. Atkinson and R. W. Grimes: J. Am. Ceram. Soc. 86 (2003) 554-559.

13) H. Yoshida, K. Okada, Y. Ikuhara and T. Sakuma: Phil. Mag. Lett. 76 (1997) 9-14.

14) H. Yoshida, Y. Ikuhara and T. Sakuma: J. Mater. Res. 13 (1998) 25972601.

15) H. Yoshida, Y. Takigawa, Y. Ikuhara and T. Sakuma: Mater. Trans. 43 (2002) 1566-1572.

16) H. Yoshida, Y. Ikuhara and T. Sakuma: Acta Mater. 50 (2002) 29552966.

17) H. Yoshida, Y. Ikuhara, T. Sakuma, M. Sakurai and E. Matsubara: Phil. Mag. 84 (2004) 865-876.

18) G. Radtke, S. Lazar and G. A. Botton: Phys. Rev. B 74 (2006) $155117-$ 1-155117-7.

19) T. P. Jones, R. L. Coble and C. J. Mogab: J. Am. Ceram. Soc. 52 (1969) 331-334.

20) R. L. Coble, H. Song, R. J. Brook, C. A. Handwerker and J. M. Dynys: Advances in Ceramics, vol. 10, ed. by W. D. Kingery, (Am. Ceram. Soc., Columbus, OH, 1984) pp. 839-852.

21) S.-J. L. Kang: Sintering-Densification, Grain Growth and Microstructure, (Elsevier Butterworth-Heinemann, MA, 2005) pp. 57-62.

22) A. S. Helle, K. E. Easterling and M. F. Ashby: Acta Metal. 33 (1985) 2163-2174.

23) M. Kitayama and A. M. Glaeser: J. Am. Ceram. Soc. 88 (2005) 34923500 .

24) K. Matsunaga, A. Nakamura, T. Yamamoto and Y. Ikuhara: Phys. Rev. B 68 (2003) 214102-1-214102-8.

25) K. P. D. Lagerlöf and R. W. Grimes: Acta Mater. 46 (1998) 5689-5700.

26) W. D. Kingery, H. K. Bowen and D. R. Uhlman: Introduction to Ceramics, (John Wiley and Sons, A Wiley-Interscience Publication, NY, 1976) pp. 36-46.

27) A. L. Allred: J. Inorg. Nucl. Chem. 17 (1961) 215-221. 